\title{
A new formulation of the protective coating for historical monuments
}

\author{
Rachid Benkmil ${ }^{*}$, Lahcen Bahi, Ahmed Akhssas, Latifa Ouadif, Driss Elhachmi , and Toufiq Ait El fakih \\ Mohammadia School of Engineers (L3GIE Laboratory), Mohammed V University, Rabat, Morocco
}

\begin{abstract}
Historic buildings are more closely tied to the ground than modern buildings. They are more porous, take water from the ground, transport it through their structure and evacuate it, generating side effects such as oxidation and crumbling. Walls and floors are the point of exchange for these reactions. An increase in the soil moisture could lead to a greater circulation of dissolved salts, and therefore to a harmful crystallization on the decorated surfaces but also to a greater instability of the soil. Our objective in this work is the choice of a plaster coating to limit damage due to climatic factors and mainly humidity. We are characterized the coating compositions firstly, and then proposed plaster based formulations. The choice of the best plank may be made by carrying out Karsten tube penetration and capillary absorption tests.
\end{abstract}

\section{Introduction}

Most of current research on the impacts of climate change focuses primarily on agriculture, biodiversity, health, and water resources, but the state of knowledge about their impact on built heritage remains limited, namely the historical monuments, which carry a cultural, and memorial message.

The consequences of climate factors on the built cultural heritage are multiple, and the assessment are difficult for several reasons, such as the complexity of the behavior patterns of building materials in historic buildings as well as the difficulty of quantifying the interaction mechanisms the present climate with the materials that make up this heritage risks making the reaction to deal the impacts of climate factors on these buildings a delicate operation [1].

Historic buildings are more intimately linked to the ground than modern buildings. They are more porous, collect water from the ground, transport it through their structure and evacuate it by evaporation, generating side effects such as oxidation and crumbling. Walls and floors are the point of exchange for these reactions. Increased soil moisture and an aggressive climate could lead to greater circulation of dissolved salts, and thus to damaging crystallization on decorated surfaces but also to greater soil instability [2].

Our objective in this work is the choice of a coating to limit the degradation due to climatic factors and essentially humidity. For this, we first characterize the compositions of the coating and then we formulate the plaster, choosing the best board by using Kartsen tube and capillary absorption tests to estimate water transport parameters of porous building materials.

\section{The traditional coating of historical monuments}

Traditional plaster has been widely used for a long time on ancient buildings, the first material used for its manufacture was mud or clay mixed with straw or pieces of cane [3], this is still used today in southern Morocco.

The first appearances of lime in the plaster were observed in Mesopotamia in VI millennia BC. JC, at this time the coating played an aesthetic role, at the time of ancient Greece, two other roles were attributed to the coating, namely the correction of irregularities and the protection of masonry [4]. This has been unveiled to overcome the fragility of a structure using materials that are sensitive to external changes.

Currently several types of coatings are used namely: earth coatings, gypsum plaster, lime renders and cement coatings. The choice of coating depends on the substrate and its usefulness. It is imperative that the plaster be in perfect compatibility with its support in order to guarantee a good implementation and to preserve the durability of the building [4].

In Morocco as elsewhere, the coatings preserved on the monuments are based on lime or plaster with multiple compositions depending on the time of their application, the lime plaster is used outside, while the plaster is used to inside. In Marrakech as in several Moroccan regions, the coating of historical monuments is achieved by applying multiple layers, this traditional lime plaster is called "The Tadelakt", it has the advantage of being waterproof and more resistant at the water [5].

\footnotetext{
* Corresponding author: rachidbenkmil@gmail.Com
} 


\section{Building Description}

The selected building is a world heritage-listed historical monument named Medersa Ben Youssef which constitutes one of the largest in the Maghreb, and the most remarkable historical monuments of the city of Marrakech. This Koranic school was founded in the early 14th century by the Moroccan monarch Abu El Hassan, enlarged by the reign of Saadians redecorated in the year 1570. The medersa was more than four centuries as home for students in various sciences [6] designed on a $1680 \mathrm{~m}^{2}$ quadrilateral plan, including 132 student rooms distributed over two floors around an inner courtyard overlooking the prayer room. The southeast and north-west perimeter walls are anchored at the level of the clay formation at a depth of one meter from the level of the paving, they are built of traditional solid bricks joined by a lime-based mortar and adobe, and rest on a base and sole composed of a traditional clay and lime-based and Rammed Earth. The south-east and north-west perimeter walls are anchored at the level of the clay formation at a depth of $1 \mathrm{~m}$ from the level of the paving, and are built of traditional solid bricks joined by a lime-based mortar and adobe, and rest on a base and sole composed of a traditional clay and lime-based rammed earth [7]. Identification tests on the materials taken from the excavations yielded an average of the value of methylene blue of $0.16(\mathrm{~g} / 100 \mathrm{~g})$, and an average water content of $25.6(\%)$, the direct shear test on the samples taken gave a cohesion of $6 \mathrm{kPa}$ and a friction angle of $30^{\circ}$.

The surveys carried out showed the existence of two building materials for the supporting walls namely the traditional solid brick with a traditional lime mortar and the rammed earth, the thickness of the walls varies between $30 \mathrm{~cm}$ and reaches up to $1 \mathrm{~m}$ in some places, and the poles are built of solid bricks.

Particle size analysis as well as the value of methylene blue (VBS) concluded that the studied material has a water-sensitive light sandy character and a varied granulometry with an average VBS value of $0.11(\mathrm{~g} / 100 \mathrm{~g})$ ), with an average water content of $25.6(\%)$. The compressive strength of the bricks used is relatively low compared to those currently existing and marketed (Table 1), with compression resistance of up to $20 \mathrm{MPa}$.

Table 1. Features of solid brick

\begin{tabular}{|c|c|c|c|c|}
\hline $\begin{array}{c}\mathbf{D D}^{(\mathrm{a})} \\
\mathbf{( k g / m 3 )}\end{array}$ & $\begin{array}{c}\mathbf{A D}^{(\mathrm{b})} \\
\left.\mathbf{( k g / m}^{\mathbf{3}}\right)\end{array}$ & $\begin{array}{c}\mathbf{P V} \\
\mathbf{( \% )}\end{array}$ & $\begin{array}{c}\mathbf{R A}^{(\mathrm{d})} \\
\mathbf{( \% )}\end{array}$ & $\begin{array}{c}\text { Cs ( }{ }^{(\mathrm{e})} \\
\mathbf{( M P a )}\end{array}$ \\
\hline 1665 & 1796 & 4,99 & 1,1 & 3,6 \\
\hline
\end{tabular}
voids, ${ }^{(d)} \mathrm{RA}$ : Absorption rate, ${ }^{(\mathrm{e})} \mathrm{Cs}$ : compressive strength

\section{Diagnosis of the building}

To have good a state of this monument, our goal is to develop a methodology for the diagnosis and restoration of this historically classified monument in order to preserve its authentic appearance from the architectural point of view, materials, epigraphy, polychromy [8].

The existing walls are built of rammed earth on some areas and solid brick on the other areas, on which was built a lime coating, named Tadelaket, on the exterior facades, and a traditional coating on a height of about 1.6 $\mathrm{m}$ and the rest plastered on the interior facades.

Moisture is one of the main factors favoring the alteration of the constructions in rammed earth and solid brick either by chemical, physical or biological means, or by direct or indirect contact [9]. There are several sources and types of humidity: ascending humidity, water infiltration, rain humidity .....

A continuous alternation of humidity and drought due to the periodicity of the rains is a major cause of the alteration of the building's materials [10].

Rainwater enters through the exterior facades as well as through the terrace, it is absorbed by the wall in rammed earth and solid brick whose thickness reaches up to $1.20 \mathrm{~m}$ in some places, over time, a gravity flow of water is carried out at inside the wall to the base sound or it removes it as moisture, Fig. 1, this leads to erosion of the wall and a peeling of the coatings.

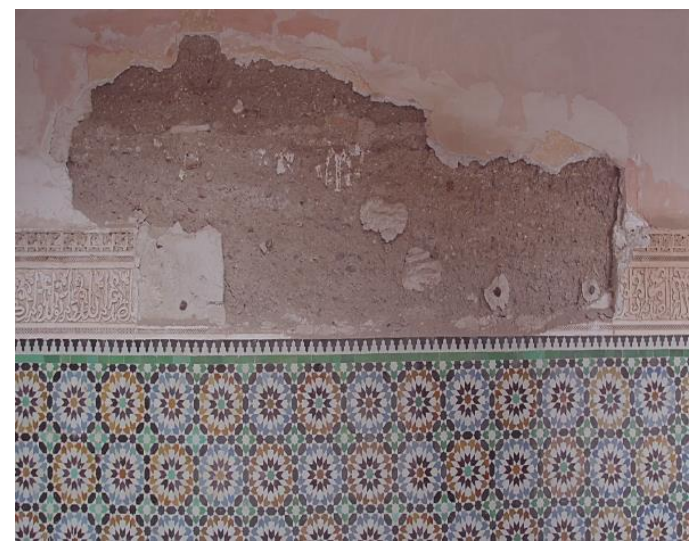

Fig. 1. Detachment of the plaster

The repetition of this mechanism leads to a heterogeneous erosion of the supporting walls, whose thickness decreases over time and consequently their resistance to compression, in fact, a study was carried out on the durability of the rammed earth showed that, under conditions or annual precipitation is about 1000 $\mathrm{mm}$, erosion of unstabilized rammed earth walls can reach $7 \mathrm{~mm}$ after 20 years [11].

The rammed earth used is an unstabilized rammed earth, the risk of erosion and degradation by moisture is much more remarkable, in fact, stabilization decreases the permeability of the rammed earth and also it increases the resistance to compression [11].

Another mechanism of degradation develops inside the building, swelling of the foot of the walls and erosion, this is the result of moisture caused by the hair up as well as by the ambient humidity, in fact, the building has a very architecture closed in some places which decreases homogeneous aeration and therefore does not promote the evaporation of the water stored by the walls. 
The water content test carried out on the rammed earth in place gave an average water content of 25.6, this confirms the hygroscopic character of the rammed earth, Fig. 3.

Also, it should be noted that the old materials in general and mainly the rammed earth, have a very important capillarity, nevertheless, the solid brick has a low capillary character compared to the rammed earth [12].

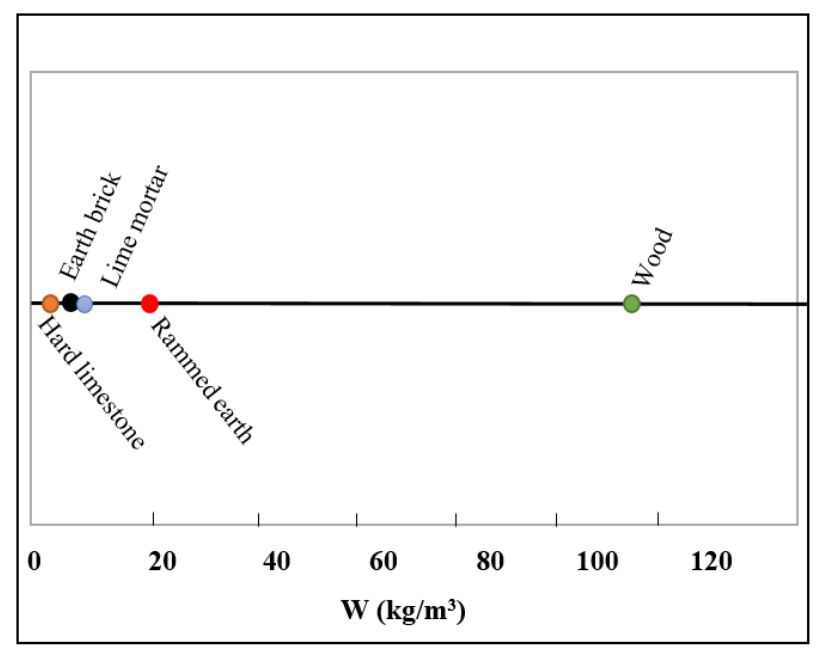

Fig. 2. Hygroscopicity of old materials (source: The notebooks "HYGROBA")

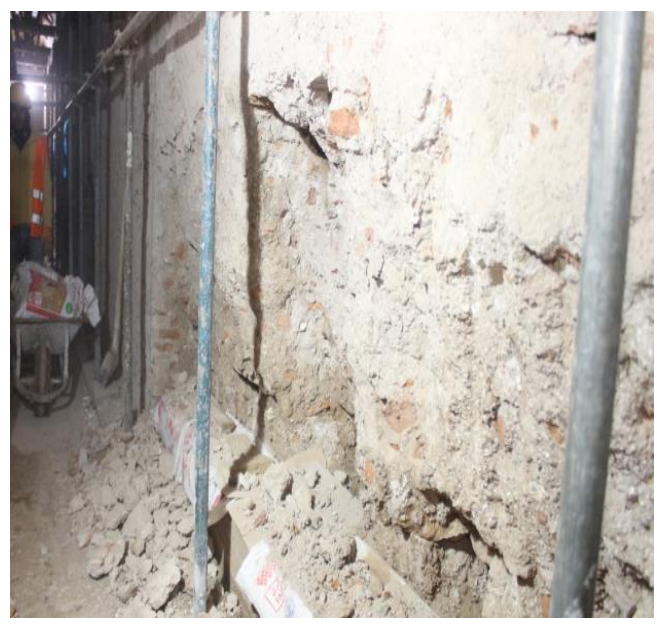

Fig. 3. Swelling and erosion of the foot of adobe walls

In our situation, the building is located in an arid climate with a aleatory distribution of precipitation due to the terrain and geographical position, a greater irregularity and variability from year to year in the evolution of precipitation and an increase in storms and high winds could lead to structural damage to the entire building [13].

On the solid brick walls, the same pathologies mentioned above are noticed but in a less serious way, other pathologies and deformations of the brick facings are observed, often related to problems of humidity, are the blooms and the damage due to frost, Fig. 4, remember that the climate of the city of Marrakech is an arid climate where the monthly extreme temperature varies between $16^{\circ}$ and $45^{\circ}$ in certain periods [14], which greatly favors the degradation process.

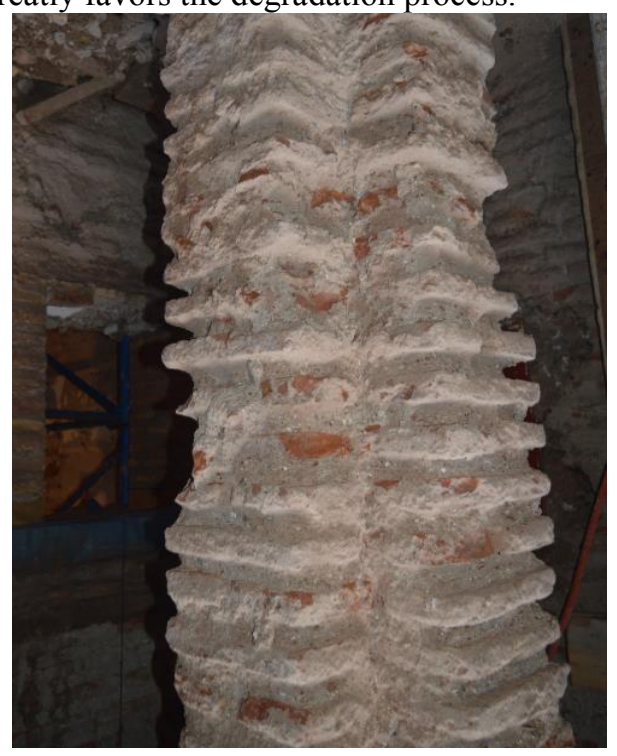

Fig. 4. Tampering of the solid brick at the low front of a pole

\section{Description of the new formulation of the plaster coating:}

The rehabilitation of a historical monument include in certain situations a partial or global stripping of the existing coat in order to define the state of preservation of its structure, the protective coat to be executed, must retain the authentic appearance of the building, ensure good grip and it must be waterproof in order to limit the contact of water with the support.

In this work, we limit ourselves to plaster coatings, commonly used in historical monuments in Morocco, and mainly the building under study, the Ben Youssef Medersa in Marrakech.

The first type of coating proposed is plaster-based with Sika adjuvant, the second type is a plaster-based coating with another liquid adjuvant "TECHNIPLATRE".

\subsection{Characterization of plaster}

Plaster is a hydraulic binder known since antiquity. It is made from a white rock called gypsum, which is a mineral species composed of dihydrated calcium sulphate $\mathrm{CaSO}_{4}-2 \mathrm{H}_{2} \mathrm{O}$.

The granulometry is an important parameter that influences the mechanical properties of plaster as well as its hydration [15]. The plaster used comes from Marrakech, and by analyzing the granulometry curve of our sample, we find that it has a tight grain size. Density, tensile strength and compressive strength are listed in the Table 2. 


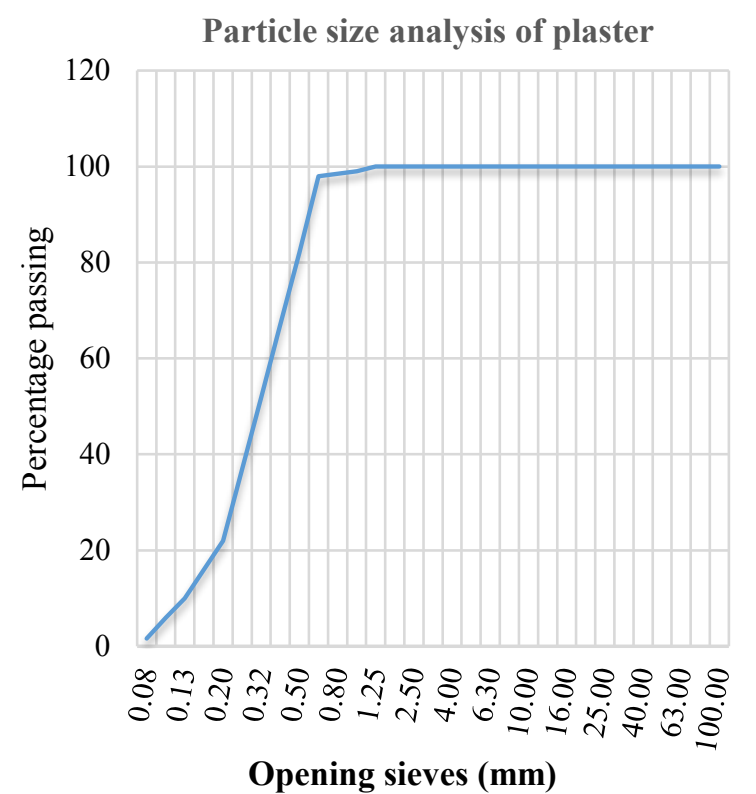

Fig. 5. Particle size analysis of plaster

Table 2. Physical and mechanical properties of plaster

\begin{tabular}{|c|c|c|c|c|c|}
\hline \multicolumn{2}{|c|}{ Particle size analysis } & $\begin{array}{c}\text { D } \\
\mathbf{t} / \mathbf{m}^{3}\end{array}$ & $\begin{array}{c}\mathbf{R}_{\mathrm{t}} \\
\mathbf{M P a}\end{array}$ & $\begin{array}{c}\mathbf{R}_{\mathbf{c}} \\
\mathbf{M P a}\end{array}$ \\
\cline { 1 - 1 }$\%<80 \mu \mathrm{m}$ & $\%<2 \mathrm{~mm}$ & $\mathrm{D}_{\max }$ & \multirow{2}{*}{0.87} & 3.6 & 15.9 \\
\cline { 1 - 2 } 1.61 & 100 & 1.6 & & & \\
\hline
\end{tabular}

\subsection{The formulation of the coating}

Three plaster-based boards were tested:

- Plank 1: Mortar Sika waterproof + Plaster + Sika latex.

- Plank 2: Sika latex + plaster.

- Plank 3: Mortar Sika waterproof + Plaster.

The Karsten tube penetration test is a simple test to measure the degree of water penetration into building materials. The test consists of a glass tube filled with water linked to the material to be tested with plastic. The water pressure then exerts on the surface. A graduated scale indicates, over time, the amount of water or penetration into the surface Fig. 6 .

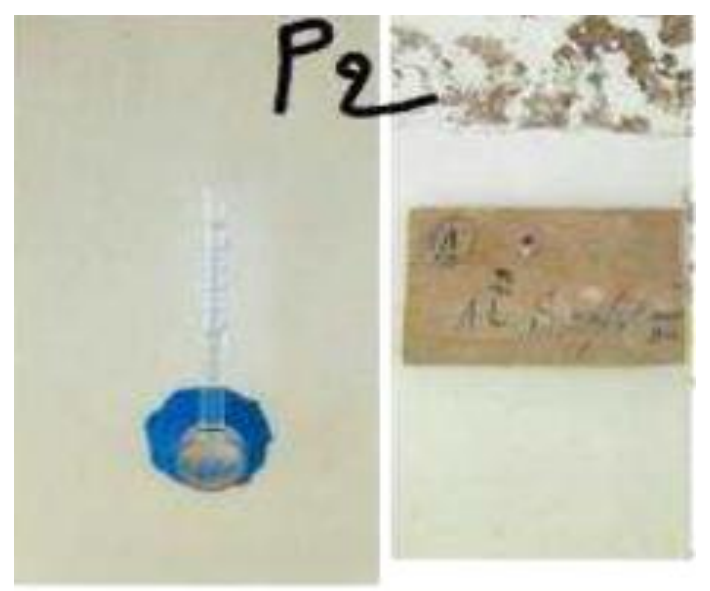

Fig. 6. Water absorption test at Kartsen tube (the test carried out in situ).

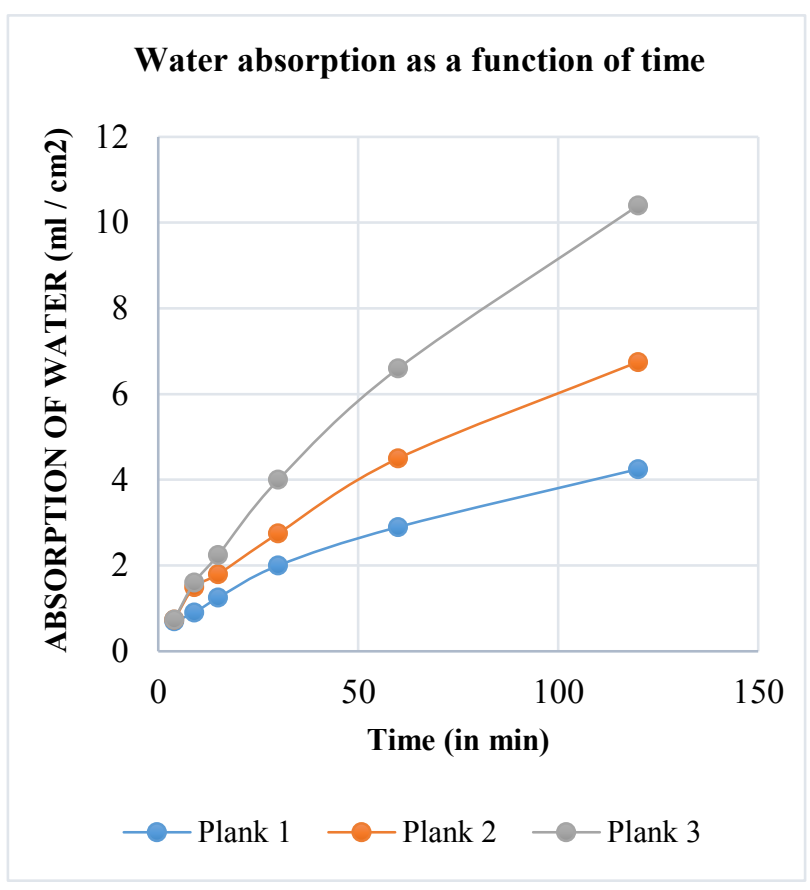

Fig. 7. Water absorption as a function of time

Through this trial, we found that the addition of adjuvants significantly improves the waterproof effect of the coating, after one hour, the mixing of plaster with Sika latex has reduced absorption by about $32 \%$ compared to the mixture of the plaster with the Sika waterproof mortar, Fig. 7.

After two hours, mixing the plaster with the Sika latex reduced the absorption by about $38 \%$ compared to the mixture of plaster with the Sika waterproof mortar, this reduction arrives up to $58 \%$ with the combination of plaster, Sika waterproof mortar and Sika latex.

The dosage used for this coating is $10 \mathrm{~kg}$ of plaster + $250 \mathrm{~g}$ of Sika Waterproof.

The second type is a plaster coating with a liquid water repellent adjuvant, Table 3 , which is evenly distributed in the plaster water mixture with a $2 \%$ dosage on dry plaster weight. 
Table 3. Properties of the adjuvant

\begin{tabular}{|c|c|c|}
\hline Density (kg/L) & $\mathbf{p H}$ & color \\
\hline 1.01 & 6.7 & White \\
\hline
\end{tabular}

The water absorption test by capillarity was carried out on $4 \times 4 \times 16 \mathrm{~cm}^{3}$ specimens, measuring water absorption under the effect of capillary forces.

The method is based on the direct measurement of the capillary ascent of a liquid. The flat side of the slightly submerged sample is placed on the surface of the water to measure the amount of water absorbed according to the root of time.

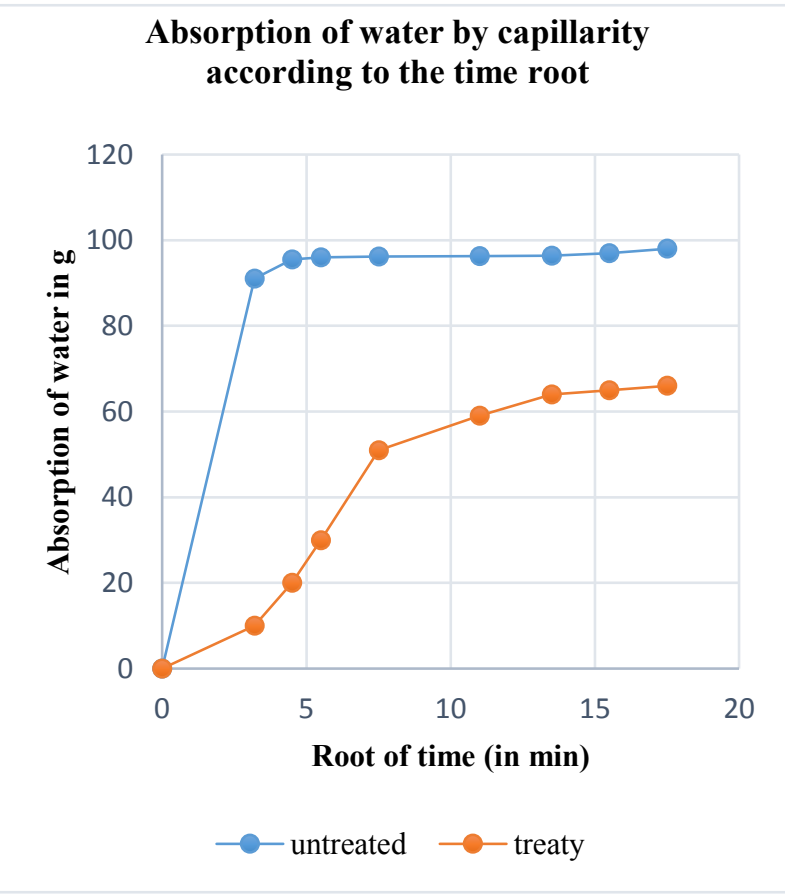

Fig. 8. Absorption of water by capillarity according to the time root

On the graph, Fig. 8, we find that the two curves obey the same laws, all the time, the addition of the adjuvant has reduced the absorption of water by $45 \%$ after one hour of exposure and $31 \%$ after 5 hours of exposure.

Another parameter can also be deduced from this test, in fact, by analyzing the evolutionary curve, we find that it consists of two segments on the right:

- The first, fairly steep slope characterizes the initial water absorption $\mathrm{A}_{\mathrm{bi}}$. This water is held by the capillaries of larger diameters located on the surface. Generally this absorption is recorded during the first hour of the test [16]. Initial absorption refers to the mass of water absorbed after one hour; this value is sufficiently representative of the average radius of the largest capillaries [16].

- The second phase of low-slope absorption characterizes the filling of the increasingly thin capillaries. The slope of this part determines the sorptivity of the material $\mathrm{S}_{\mathrm{c}}$. The term sorptivity generally refers to the rate of absorption during phase II [17].For the study of durability, the initial water absorption is a very useful parameter to characterize the durability of a material to aggressive agents.

On the graph, Fig. 9, we find that the initial water absorption is very important for the untreated sample by the adjuvant, this reflects the volume of the larger capillaries it contains, indeed, the initial absorption is a representative parameter of the size of the large capillaries [18]. Therefore, the untreated sample is more sensitive to the penetration of aggressive agents, which influences its durability [19].

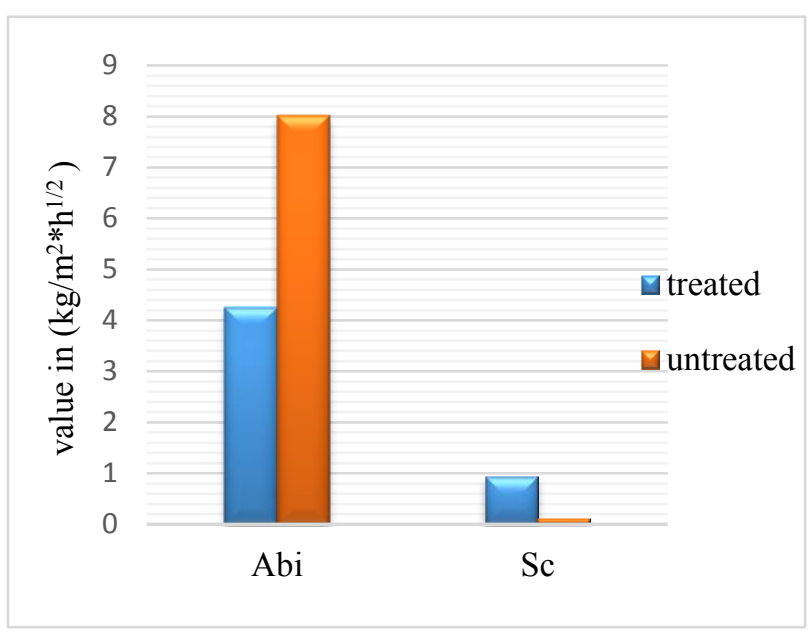

Fig. 9. Initial water absorption and sorptivity of prepared samples

In the second phase, the untreated sample has a greater sorptivity than the treated sample, this may mean that the addition of the adjuvant tends to slow down the kinetics of water absorption within the microstructure pores, let us recall in this sense, that some studies have shown that sorptivity is influenced not only by porosity but also by the distribution of pores [20].

\section{Conclusion}

Preliminary results presented in this article do not allow us at this stage to finely determine the most suitable material for historical monuments; however, significant advances can be identified from the results obtained:

- Mixing Sika latex with plaster has allowed the absorption by about $32 \%$ compared to the mixture of plaster with Sika waterproofing mortar.

- After two hours, mixing the plaster with the Sika latex reduced the water absorption by about $38 \%$ compared to the mixture of plaster with the Sika waterproof mortar, this reduction arrives up to $58 \%$ with the combination of plaster, Sika waterproof mortar and Sika latex.

- Initial water absorption is very important for the sample not treated by the liquid adjuvant "TECHNIPLATRE", therefore it is more sensitive to 
the penetration of aggressive agents, and therefore less durable.

- The sorptivity of the untreated sample is slightly important compared to the treated sample, this may mean the development of a mechanism to slow down the kinetics of water absorption within the spray and redistribution of pores at the within the macrostructure.

It should be noted that the application of these formulations could not guarantee good results without a combination with protection of the perimeter of the walls underwork by a peripheral drainage system.

The data mentioned in this article are the first steps in an in-depth study, chemical tearing and characterization tests will be carried out with the aim of obtaining the most suitable material for historical monuments.

\section{References}

[1] S. Kanani, H. Zandi, "A Study of the Damages to Historical Monuments due to Climatic Factors and Air Pollution and Offering Solutions," IJHSS, 5 (2011)

[2] D. ELHACHMI, L. BAHI, L. OUADIF, R. BENKMIL, "Diagnosis of the enclosure of the medina of salé in morocco - case of rectangular towers," (IJCIET), 10, 05, 1132-1146, (2019)

[3] A. Moropoulou, A. Bakolas, S. Anagnostopoulou , "Composite materials in ancient structures," Cement and Concrete Composites, 27, pp. 295-300, (2005)

[4] M. Riadh LABIADH, "Etude et formulations d'enduits de restauration :Applications aux monuments historiques de Ghar El Melh," Tunis, (2009)

[5] A. El Amrani, C. Polidoro, M. Ibnoussina, F. Fratini, S. Rescic A. Rattazzi, D. Magrini, "From the stone to the lime for Tadelakt: Marrakesh traditional plaster," J. Mater. Environ. Sci., 9, 3, 754-762, (2018)

[6] M. KNIDIRI, Marrakech: History, Heritage, Culture and Spirituality., Barcelone: Montada Forum, (2011)

[7] R. Benkmil, L. Bahi, A. Akhssas and L. Ouadif, "Contribution to the caracterization of construction materials of historical monuments -case study," International Journal of Civil Engineering and Technology (IJCIET), 9, 4, p. 1680-1688, (2018)

[8] ICOMOS, International charter on conservation and restoration of monuments and sites (charter of venice 1964), (1964)

[9] S. Belhaj, L. Bahi and A. Akhssas, "Study of Moroccan Monumental Heritage Traditional for Valorization and Conservation of Collective Memory and for Socio-Eco- Tourism Sustainable Development-case Kasbah Chellah,Rabat," Energy Procedia, 97, 531-538, (2016)

[10] R. EZZDINE, "Damage of historic monuments in masonry," Bordeaux.

[11] Quoc-Bao, BUI, "Stability of rammed earth structures: durability, mechanical characteristics," Lyon,(2008)

[12] Laboratory Materials and Durability of Constructions, CETE East, Study of hygrothermal rehabilitation of ancient walls, Les cahiers HYGROBA, Toulouse, (2013)

[13] UNESCO, "Climate change and world heritage," UNESCO World Heritage Center, Paris, (2009)

[14] Y. KOURAISS , K. A. BRAHIM, "Climate change in Marrakech (Morocco) Recent developments and future projections," Marrakech, (2010)

[15] C. MARTIAS, "Synthesis and characterization of composite materials based on calcium sulphate for fire protection," Toulon, (2011)

[16] J. Grandet, P. BalayssacCh ,H. DetricheJ, "Interest of the water absorption test for the characterization of concrete embedding," Materials and Structures, pp. 226-230, (1993)

[17] M. Rabehi, "Contribution to the characterization of the open porosity of asphalt concrete by the use of capillary absorption tests," Biskra, (2014)

[18] E. Wirquin, R. Hadjieva-Zaharieva and F. BuyleBodin, "Use of concrete water absorption as criteria for their durability - Application to recycled aggregates," Materials and Structures, pp. 403-408, (2000)

[19] L. Berredjem, N. Arabi, L. Molez, "Contribution to the study of the durability of concretes based on recycled aggregates.," in 33rd Meeting of AUGC ,ISABTP/UPPA, Anglet, (2015.)

[20] J. Liu "Experimental study of the relative permeability of cementitious materials and numerical simulation of water transfer in concrete," Lille, (2011) 